\title{
Digital transforming capability and performance: A microfoundational perspective
}

\author{
Thayla Zomer, Andy Neely and Veronica Martinez \\ Center for Digital Built Britain. Cambridge Service Alliance \\ Institute for Manufacturing, Department of Engineering, University of Cambridge \\ 17 Charles Babbage Road, Cambridge, CB3 OFS, UK
}

\begin{abstract}
Purpose - Drawing on the literature on dynamic capabilities and digital transformation, this paper conceptualises and investigates the relevant antecedents of an essential capability for digital transformation - the digital transforming capability - and its effect on the competitive advantage of firms.
\end{abstract}

Design/methodology/approach - A framework with individual and organisational microfoundations of the digital transforming capability is proposed based on previous research. The digital transforming capability is conceptualised as a second-order construct. The model is tested using data from a broad spectrum of large US companies. Structural equation modelling (SEM) is applied to test the proposed framework.

Findings - The study identifies three main microfoundations that, when combined, build a digital transforming capability (digital-savvy skills, digital intensity and context for action and interaction); in addition, the study tests the relationship between digital transforming capability and firm performance. The results validate the proposed theoretical framework. In addition to proposing relevant microfoundations of the digital transforming capability, we advance knowledge on the performance effects of those microfoundations.

Originality/value - The paper contributes to advancing the understanding of the digital transformation phenomenon by revealing the role of the primary components underlying the digital transforming capability. Yet the mechanisms by which the micro-level aspects are important for digital transformation and organisational outcomes are only suggested by anecdotal evidence. The paper also contributes to ongoing calls for further investigation to extend the understanding of the microfoundations of dynamic capabilities. Finally, by drawing on archival data, this study also contributes to calls to broaden the toolkit used in dynamic capabilities research. 
Zomer T., Neely A. and Martinez V. Digital transforming capability and performance: A microfoundational perspective. International Journal of Operation and Production Management. (Accepted 22/04/20) DOI: 10.1108/IJOPM-06-2019-0444

Keywords: Digital transformation, dynamic capabilities, firm performance. 
Zomer T., Neely A. and Martinez V. Digital transforming capability and performance: A microfoundational perspective. International Journal of Operation and Production Management. (Accepted 22/04/20) DOI: 10.1108/IJOPM-06-2019-0444

\section{Introduction}

Embracing the opportunities offered by digital transformation - a multifaceted phenomenon that originates from the exploitation of a bundle of evolving digital technologies in a fast-paced landscape (Lanzolla et al., 2018) and the transformation of organisations attempting to exploit these technologies (Warner and Wager, 2019) - is one of the main challenges and priorities of contemporary firms. The current management and operations management literature is almost unanimous in suggesting that digital transformation has dramatically affected - and will continue to affect - all industrial sectors (Hess et al., 2016; Sebastian et al., 2017; Lanzolla et al., 2018; Frank et al., 2019). Many industry-focused reports have emerged in recent years analysing digital transformation in a range of industrial settings, and there have been claims, in both industry- and academic-related literature, that successful digital transformation initiatives lead to improved and sustained performance (Kane et al., 2015; 2017; Dalenogare et al., 2018; Vial, 2019; Tortorella et al., 2020). On the other hand, many of the industryfocused studies also highlight that, despite the promising performance gains, most organisations fail in their initiatives, with failure rates lying in the range of $60 \%$ to $85 \%$ (Sailer et al., 2019).

Indeed, recent studies have highlighted that digital transformation is a complex and challenging phenomenon (Hess et al., 2016), and it remains poorly understood in both theory and practice (Parviainen et al., 2017; Lanzolla et al., 2018; Loonan et al., 2018; Vial, 2019). Undoubtedly, digital transformation is even more difficult to achieve than traditional change efforts (Martin, 2018), as it involves a continual adaptation to a constantly changing environment - the need for transformation does not lessen, even if organisations successfully 'transform' (Kane, 2017). Despite the word 'transformation', digital transformation is not a process that will ever be completed - by the time that organisations adapt to today's digital environment, that environment is likely to have already changed significantly (Kane, 2017). Companies worldwide are facing the challenge of managing the fast and repetitive adaptation of their organisations to suit the volatile circumstances of the digital age (Sailer et al., 2019). Unlike traditional transformations, the target state continuously evolves, and the flexibility required to compete in a digital environment contradicts the common approaches of many traditional organisations (Sailer et al., 2019).

Scholars have acknowledged that resources and new capabilities are necessary to effectively compete in a digital age (Liu et al., 2011; Vial, 2019; Warner and Wager, 2019). On the other hand, there has been a long debate in the dynamic capabilities' literature on whether or not 
Zomer T., Neely A. and Martinez V. Digital transforming capability and performance: A microfoundational perspective. International Journal of Operation and Production Management. (Accepted 22/04/20) DOI: 10.1108/IJOPM-06-2019-0444

dynamic capabilities have the potential to explain sustainable competitive advantage in rapidly changing environments, where the strategic imperatives are speed and adaptability (Eisenhardt and Martin, 2000; Peteraf et al., 2013). Previous research on technology implementation, such as advanced manufacturing technology implementation, has identified a range of factors and conditions that are related to successful technology adoption and implementation, such as the need for fit between technologies employed by the firm and the firm's strategy (Kotha and Swamidass, 2000), heavy investments in technology (Jonsson, 2000) and infrastructure (Boyer et al., 1997), institutional changes, long-term outlook and financial commitment, team structure, leadership and education, top-down planning (Co et al., 1998), organisational culture (McDermott and Stock, 1999), and so on. Recently, there have been emerging studies on how manufacturing companies implement new digital technologies (Dalenogare et al., 2018; Frank et al., 2019). Additionally, there has been a range of studies in the past on the capabilities necessary for innovation, such as those necessary for business model innovation and the transition to services in manufacturing firms (Gebauer et al., 2017). However, digital transformation is not only about technology implementation (Kane, 2017), and it is not similar to a transformation or change process in moderately dynamic markets. Digital technologies accelerate the speed of change, resulting in more volatility, complexity and uncertainty (Loonam et al., 2018; Warner and Wager, 2019).

Recently, empirical research has identified that incumbent firms need new digital sensing, digital seizing and digital transforming dynamic capabilities to compete in a digital economy (Warner and Wager, 2019). The aforementioned authors argue that, in contrast to non-digitalbased strategic change, the ubiquity of new digital technologies changes the nature of the requisite dynamic capabilities, as organisations can, and indeed need to, scale up or down their operations, as it was not possible before, for example, in terms of speed; they also need to be more entrepreneurial (Warner and Wager, 2019). In the same vein, other scholars have suggested that there are capabilities that have general applicability to firms and remain useful to the firm even in high-velocity environments when the conditions constantly change, as in the case of a digital economy (Peteraf et al., 2013).

Incumbent firms, however, are facing considerable challenges to build and maintain the new digital capabilities needed to compete in a high-velocity environment compatible with the path dependencies of the past (Svahn et al., 2017). Organisations tend to become more static over time, and the necessary adaptability can be difficult to maintain, even if it is established (Warner and Wager, 2019). The dynamic capabilities in place need to address the reality of a 
Zomer T., Neely A. and Martinez V. Digital transforming capability and performance: A microfoundational perspective. International Journal of Operation and Production Management. (Accepted 22/04/20) DOI: 10.1108/IJOPM-06-2019-0444

fast-evolving digital environment, one that is in constant change and which requires constant change. However, previous studies have already noted that operations management executives, for instance, despite realising the importance of continuous improvement, find managing continuous change and improvement a challenging task (Anand et al., 2009). The challenge lies in creating an infrastructure to coordinate the continuous improvement efforts (Anand et al., 2009). Industry-focused studies have also found that, indeed, digitally maturing organisations, those that achieve better results, are the ones that tend to 'pull' digital transformation by cultivating the conditions that are ripe for the transformation to occur (Kane, 2017).

Although recent empirical research has suggested which dynamic capabilities are necessary to compete in a digital economy, and has identified a range of sub-capabilities of those capabilities (Warner and Wager, 2019), it remains unexplored in the academic literature if those capabilities are related to performance improvements or sustained performance, and/or what are the micro-level aspects to build those capabilities that lead to improved and sustained performance in the digital age. The conditions that are ripe for the transformation to occur, or the building blocks, have only been discussed in non-academic literature (Kane, 2017). The micro-level components of dynamic capabilities, however, have assumed greater importance in the search for the factors that facilitate strategic change (Helfat and Peteraf, 2015) and explain performance heterogeneity among firms (Felin et al., 2012), but they remain unexplored in the context of the digital economy (Vial, 2019; Warner and Wager, 2019). A microfoundational approach is relevant because it focuses on collective phenomena that need explanations, specifically regarding their creation and development, and addresses lower-level entities (Felin et al., 2012).

Thus, in this paper, in alignment with recent research, we assume that there are capabilities that are useful for organisations to remain competitive in the high-velocity environment of a digital economy (Peteraf et al., 2013; Warner and Wager, 2019). We focus on how firms build those capabilities, specifically, the capability of executing a digital transformation strategy, as identified by Warner and Wager (2019) - that is, the digital transforming capability. While digital sensing and digital seizing capabilities, as already identified by previous research and reframed by Warner and Wager (2019) in the context of a digital economy, help to create and discover opportunities, it is the digital transforming capability that it is necessary to execute in order to realise the full potential of strategic change (Warner and Wager, 2019), it being a critical capability for incumbent firms to compete in a digital age. We draw on the literature on 
Zomer T., Neely A. and Martinez V. Digital transforming capability and performance: A microfoundational perspective. International Journal of Operation and Production Management. (Accepted 22/04/20) DOI: 10.1108/IJOPM-06-2019-0444

the microfoundations of dynamic capabilities and the existing academic and industry-related research on digital transformation to investigate the following research question: What are the building blocks of the digital transforming capability that lead to sustained business performance in a digital economy environment?

The micro-level aspects that determine the development of the capability of firms to execute a digital transformation strategy and reconfigure their resource bases in a constantly changing digital landscape, and which lead to performance gains, are investigated in this study. By investigating the primary components underlying the digitally transforming capability, this paper contributes to the literature in different ways. First, we extend recent research (Warner and Wager, 2019) by investigating the micro-level components that underpin a firm's digital transforming capability, or its origins. We disaggregate the organisation-level construct into some constituent microfoundations (both organisational and individual factors) that shape the digital transforming capability, and we test the relationship between the digital transforming capability (as built by those primary components) and firm performance. Research into capabilities, as in the case of recent research on the capabilities for digital transformation, has generally been located at organisational level, while much less has been said about the microlevel factors that help to build those capabilities (Loon et al., 2020). The mechanisms by which micro-level aspects matter to digital transformation and organisational outcomes were only indicated by anecdotal evidence, and there is a lack of comprehensive understanding of the phenomenon (Vial, 2019).

Second, by exploring those micro-level elements we also contribute to ongoing calls in the dynamic capabilities literature for further investigations to broaden the understanding of its microfoundations (Fainshmidt and Frazier, 2017; Bendig et al., 2018; Schilke et al., 2018; Loon et al., 2020). While proliferating studies have suggested that dynamic capabilities are important to competitive advantage, the antecedents of dynamic capabilities remain generally understudied (Fainshmidt and Frazier, 2017). Although scholars have posited that there are capabilities that are valuable for firms in high-velocity environments (Peteraf et al., 2013), the organisational and individual aspects that lead to the creation of those capabilities, and the relationship with firms' performance, have not been explored and tested. The study of the microfoundations of capabilities, specifically the digital transforming capability, however, may enrich both the theoretical understanding and practical knowledge of how firms create sustainable advantage (Loon et al., 2020). In addition, the research design adopted in this 
Zomer T., Neely A. and Martinez V. Digital transforming capability and performance: A microfoundational perspective. International Journal of Operation and Production Management. (Accepted 22/04/20) DOI: 10.1108/IJOPM-06-2019-0444

research, which is drawn from archival data, contributes to recent calls to broaden the toolkit used in dynamic capabilities research (Schilke et al., 2018).

Third, there have been calls in the operations management literature for more research identifying the inputs (root causes) influencing the performance of firms (Hasegan et al., 2018). The findings of this research, therefore, reveal the contribution of micro-level aspects or the role of the primary components underlying an important capability that leads to improved and sustained performance, which is crucial because the development of the field requires the research to be expanded to encompass multi-level effects, including micro-level ones (Felin et al., 2012).

Finally, the current study analyses digital transformation across different industries and identifies cross-sector common micro-level factors that lead to the development of the digitally transforming capability and improved performance. So far, other studies have focused on the digital transformation of single industries (Kretschmer and Claussen, 2016), and there have been calls for cross-industry research (Khin and Ho, 2019; Lanzolla et al., 2018).

The remainder of this paper is structured as follows. In the next section, a theoretical model for the microfoundations of digital transforming capability is proposed. Then, a detailed account of the data and analyses is provided to confirm that the theorised constructs load into specific underlying components, followed by a discussion of the main findings. We conclude by summarising the main implications, providing the research limitations and giving suggestions for further research.

\section{Theoretical background}

The digital transformation phenomenon has been conceptualised as the use of new digital technologies to enable major business improvements, such as enhancing customer experience, streamlining operations or creating new business models (Warner and Wager, 2019). These new digital technologies include, for instance, social, mobile, analytics, cloud and Internet of Things (IoT) technologies (Sebastian et al., 2017). Many of these technologies, such as IoT and big data and analytics, have been widely applied in a range of sectors, as in the case of manufacturing firms (Frank et al., 2019). The term 'transformation' expresses the comprehensiveness of the actions that need to be taken when incumbent organisations are faced with those new and evolving technologies (Singh and Hess, 2017). However, as previously mentioned, the need for transformation does not lessen, even if organisations successfully 'transform' (Kane, 2017). 
Zomer T., Neely A. and Martinez V. Digital transforming capability and performance: A microfoundational perspective. International Journal of Operation and Production Management. (Accepted 22/04/20) DOI: 10.1108/IJOPM-06-2019-0444

Although attention on the topic has increased in recent years, the understanding of how organisations implement digital transformation initiatives remains limited and fragmented (Loonam et al., 2018). Recently, studies have started to emerge on, for example, how manufacturing firms implement digital technologies; or, in other words, what is needed for the effective implementation of new digital technologies (Frank et al., 2019), how digital technologies are integrated into existing production systems (Tortorella and Fettermann, 2018) and the new business models in manufacturing firms driven by digital technologies (Weking et al., 2019). Research has also posited that digital transformation has a positive impact on firms' performance (Dalenogare et al., 2018), and studies have started to emerge to understand the role of, for example, organisational learning capabilities and how they mediate the association between digital technologies and operational performance (Tortorella et al., 2020).

On the other hand, scholars and industry practitioners recognise that digital transformation is not only about new technology implementation in a singular process that occurs and is then completed (Kane, 2017). Many have posited that firms need new dynamic capabilities to remain competitive in the digital age (Svahn et al., 2017; Raj et al., 2019). Firms not capable of developing those capabilities are likely to be left behind in the highly dynamic environment of a digital economy (Raj et al., 2019). The efficacy of the responses to gain or maintain competitive advantage is dependent on the ability of firms to sense disruptions, seize them and reconfigure elements of their business accordingly and constantly (Vial, 2019).

From a theoretical perspective, the dynamic capabilities framework has been proposed as a theoretical foundation to study the mechanisms that enable firms to engage with digital transformation (Vial, 2019). The applicability of this framework to high-velocity environments, as in the case of a digital economy landscape, however, has been under debate in the dynamic capabilities' literature, as is discussed next.

\subsection{Dynamic capabilities in high-velocity environments}

The dynamics capabilities framework (Teece et al., 1997) has attracted considerable attention within the management, operations and innovation literature in recent decades as a theoretical lens to explain how firms can sustain competitive advantage and obtain superior performance. The dynamic capability perspective extends the static perspective of the resourcebased view (RBV) of the firm by focusing on the purposeful modifications of the resource base to fit with the external environment and ensure firms' survival (Schilke et al., 2018). Teece et al. (1997, p. 516) conceptualise dynamic capabilities as 'the firm's ability to integrate, build, 
Zomer T., Neely A. and Martinez V. Digital transforming capability and performance: A microfoundational perspective. International Journal of Operation and Production Management. (Accepted 22/04/20) DOI: 10.1108/IJOPM-06-2019-0444

and reconfigure internal and external competencies to address rapidly changing environments'. This perspective has captured the attention of scholars because it offers a route with which to gain a competitive advantage under conditions of change (Schilke et al., 2018).

The dynamic capabilities concept is one of the most actively researched, yet at the same time controversially discussed, theories in the existing literature (Bendig et al., 2018). Indeed, the dynamic capabilities field has developed under the influence of two contrasting perspectives - Eisenhardt and Martin (2000) and Teece et al. (1997) - which are contradictory, especially regarding the boundary conditions of these frameworks and whether dynamic capabilities can be a source of competitive and sustainable advantage (Peteraf et al., 2013). Actually, the papers represent two mutually exclusive approaches for framing dynamic capabilities. While Eisenhardt and Martin (2000), for example, discuss specific types of dynamic capabilities, Teece et al. (1997) offer a more general account of those capabilities. The most evident difference between the two frameworks, however, concerns the boundary conditions that describe when and where the dynamic capabilities perspective can answer the question of whether firms can sustain competitive advantage (Peteraf et al., 2013). Teece et al.'s (1997) conceptualisation of dynamic capabilities per se emphasises environments of rapid technological change. In contrast, Eisenhardt and Martin (2000) point out that the resourcebased logic that frames Teece et al.'s (1997) conceptualisation of dynamic capabilities has a boundary condition in high-velocity markets, as those markets are in a continuously unstable state, and therefore capabilities become more difficult to sustain (Peteraf et al., 2013). Moreover, the two frameworks also contrast in terms of whether firms can attain and sustain competitive advantage (Peteraf et al., 2013). While Teece et al. (1997) suggest that dynamic capabilities are a source of competitive advantage per se, and the durability of the advantage depends on how readily the capability can be cloned by a competitor, Eisenhardt and Martin (2000) argue that dynamic capabilities can be a source of competitive, but not sustainable, advantage. The conceptualisation of dynamic capabilities by Eisenhardt and Martin (2000) as best practices asserts that replicable best practices are not likely to constitute a dynamic capability. In this sense, the conceptualisation of dynamic capabilities proposed by Eisenhardt and Martin (2000) implies that any competitive advantage that is attributable to dynamic capabilities is likely to be small (Peteraf et al., 2013).

Aiming to bridge the theoretical divide, scholars such as Peteraf et al. (2013) have proposed ways of integration across the two contrasting frameworks. The conceptualisation of dynamic capabilities in high-velocity environments is of particular interest, as recent studies have 
Zomer T., Neely A. and Martinez V. Digital transforming capability and performance: A microfoundational perspective. International Journal of Operation and Production Management. (Accepted 22/04/20) DOI: 10.1108/IJOPM-06-2019-0444

posited that firms need new dynamic capabilities to compete in a fast-paced digital landscape. One of the ways that Peteraf et al. (2013) proposed that sustainable advantage in high-velocity markets can be realised is through the assumption that the rules and routines, as proposed by Eisenhardt and Martin (2000), vary in their level of specificity. This view suggests that there might be rules and processes that have more general applicability, and those remain useful to firms even if conditions change, providing a source of sustainable competitive advantage even in high-velocity markets (Peteraf et al., 2013). In alignment with this perspective, the dynamic capabilities to compete in a fast-paced digital landscape can be thought of as capabilities that remain useful to firms even if the digital environment changes.

However, the question that remains is how organisations build those capabilities (Vial, 2019; Warner and Wager, 2019). Scholars have called for more research into the microfoundations that help to understand and explain how a continuous digital transformation unfolds in practice (Vial, 2019). Indeed, building and maintaining dynamic capabilities are anchored in micro-level elements, such as the performance of individuals (Vial, 2019). Those micro-level aspects have been proposed in the dynamic capabilities literature as differentiators of organisational behaviour and performance (Felin et al., 2012). The microfoundations enhance the understanding of the primary components underlying routines and capabilities, and therefore they can contribute to explaining performance heterogeneity among firms.

Industry-focused studies have identified a range of micro-level aspects that distinguish digitally mature and successful firms from less digitally mature firms. On the other hand, recent academic research has identified a range of sub-capabilities for the proposed dynamic capabilities for digital transformation (Warner and Wager, 2019). The micro-level components that build those dynamic capabilities or sub-capabilities, in a way that explains heterogeneity in competitive advantage, however, have not been analysed in the academic literature. We turn to the understanding of how those micro-level components may translate into improved performance, namely, by facilitating the development of an important dynamic capability for the unfolding of the digital transformation process, the digital transforming capability.

\subsection{Building blocks of the digital transforming dynamic capability}

Although the digital transformation literature is still in its early stages in identifying the mechanisms that enable firms to engage with digital technologies to enable strategic renewal (Vial, 2019), recent research has emphasised the importance of three dynamic capabilities to obtain digital transformation (Warner and Wager, 2019). Firms need strong dynamic 
Zomer T., Neely A. and Martinez V. Digital transforming capability and performance: A microfoundational perspective. International Journal of Operation and Production Management. (Accepted 22/04/20) DOI: 10.1108/IJOPM-06-2019-0444

capabilities to sense, seize and transform, along with a good strategy (Teece, 2014) to remain competitive in the digital age.

Sensing (and shaping) new opportunities is related to scanning, creation, learning and interpretive activity (Teece, 2007). Companies need sensing capabilities to predict the latest digitalisation trends in a fast-paced environment (Warner and Wager, 2019), and for the continuous refinement of digital transformation strategies. Organisations pursuing a digital transformation need to be prepared to continuously navigate the dynamic and emerging digital landscape (Sia et al., 2016). Seizing capabilities involves making high-quality investment decisions (Hodgkinson and Healey, 2011). Once a new opportunity has been sensed, firms need to exploit them through a new business model design and make decisions about investments because, here, multiple paths are possible (Teece, 2007). Becoming a digital business involves considering, for instance, whether the firm should optimise the existing business model or introduce new business models and revenue sources (LeHong and Waller, 2017). The best path for a particular company depends on its strategic objectives, industry context, competitive pressures and customer expectations (Berman, 2012).

Finally, to execute a digital strategy, companies need a digital transforming capability (Warner and Wager, 2019). The strategic renewal associated with a digital transformation requires the capability to modify the organisation's resource base (Agarwal and Helfat, 2009). In this paper, we focus on this capability because of its relevance to executing the digital transformation strategy; in other words, firms may sense and seize opportunities, but a firm's transformation and competitive advantage depend on its ability to transform its business model and resource base, namely, to execute the strategy (Warner and Wager, 2019). This capability also provides insights into the full range of complexities associated with digital transformation (Warner and Wager, 2019), and investigating this may provide valuable insights into the antecedents of a successful digital transformation. Indeed, reconfiguration capabilities may support the promotion of high evolutionary fitness (Wilden et al., 2013), enabling the organisation to survive and grow in the digital era and resulting in performance improvements over time. Therefore, we posit that, in order to maintain its competitiveness, an organisation needs to have the capability to constantly transform its broader resource base to execute digital strategies, and we focus on the components of this capability.

The literature also recognises that an explanation of dynamic capabilities at organisational level requires considering lower-level entities, such as individuals and processes (Teece, 2007; Felin et al., 2012). Although recent studies recognise the relevance of the dynamic capabilities 
Zomer T., Neely A. and Martinez V. Digital transforming capability and performance: A microfoundational perspective. International Journal of Operation and Production Management. (Accepted 22/04/20) DOI: 10.1108/IJOPM-06-2019-0444

framework to understand the digital transformation phenomenon (Warner and Wager, 2019; Vial, 2019), the roots of those dynamic capabilities have not been explored in detail. However, focusing on the micro-level is relevant to understanding the factors that promote the change (Helfat and Peteraf, 2015) that are the differentiators of sustained performance (Felin et al., 2012).

Teece (2007) defines the microfoundations of dynamic capabilities as the distinct skills, processes, procedures, organisational structures, decision rules and disciplines that support the sensing, seizing and reconfiguring abilities. Felin et al. (2012) define microfoundations as a theoretical explanation supported by an empirical examination at an analytical level N-1 of a phenomenon located at an analytical level N.

Turning to the digital transformation literature, in a recent study Warner and Wager (2019) explored how organisations build dynamic capabilities for digital transformation, revealing nine digitally based sub-capabilities or microfoundations that underpin the building of digital sensing, digital seizing and digital transforming capabilities (Warner and Wager, 2019). This research, however, has not explored the constituent components of these sub-capabilities. Other studies reveal some of the microfoundations of digital capabilities, but they focus either on operational capabilities and/or specific digital capabilities, and not dynamic capabilities (e.g. Akter et al., 2016; Wamba et al., 2017; Mikalef et al., 2019).

Industry-related reports have identified a range of organisational and individual aspects related to a successful digital transformation and improved performance (e.g. Kane et al., 2016). We build on past empirical research, therefore, to investigate the microfoundations of the digital transforming capability and the relationship with performance. We also draw on the categorisation of the capabilities' microfoundations proposed by Felin et al. (2012) to propose that firms need a combination of microfoundations related to people, processes and structure to build a digital transforming capability.

Individuals have served as the microfoundations of capabilities in various ways (Felin et al., 2012). Scholars have identified that the knowledge and experience of individuals matter, and previous research has posited that individual skills and abilities are central for understanding organisation-level outcomes (Felin et al., 2012). Teece (2012) points out that dynamic capabilities are based on the skills and knowledge of executives, and that top management's entrepreneurial and leadership skills are required to develop and sustain dynamic capabilities. Other studies have identified that senior leadership has a particular influence on the development of firms' dynamic capabilities (Bendig et al., 2018). 
Zomer T., Neely A. and Martinez V. Digital transforming capability and performance: A microfoundational perspective. International Journal of Operation and Production Management. (Accepted 22/04/20) DOI: 10.1108/IJOPM-06-2019-0444

Empirical research on digital transformation has also acknowledged the role of top management and their experience and skills in promoting and executing digital transformation (Kane et al., 2016; Sawy et al., 2016). Empirical evidence has demonstrated that what separates digital leaders from others is a clear digital strategy and leadership poised to drive the transformation (Kane et al., 2016). Digital leaders need key skills, such as digital competence, change management and inspirational skills (Singh and Hess, 2017). Chief digital officers (CDOs) have been appointed and recognised as critical evangelists in organisations and as the facilitators of enterprise-wide and evolving change, although many organisations still address digital innovation through existing executive roles, such as chief information officers (CIOs) (Tumbas et al., 2017). Indeed, Warner and Wager (2019) posit that one of the sub-capabilities of the digital transforming capability is improving digital maturity, and their empirical analysis has identified that organisations need transformational leadership in order to constantly renew and execute digital strategies. Their empirical analysis identified that in two different organisations, although the job description of senior managers was the same, the ways that those managers interpreted and executed their jobs were completely different, which confirms that individuals are a source of heterogeneity on how digital transformation unfolds.

Moreover, Kane et al. (2017) have identified in an industry-focused study that digitally mature companies have focused on having sufficient digital talent in their workforce and leadership. In the same vein, Warner and Wager (2019) point out that recruiting digital natives is necessary to execute a digital transformation strategy. Previous research has also identified the impact of individuals entering organisations on the organisational capabilities (Felin et al., 2012). Therefore, we posit that digital skills at leadership and workforce levels are subdimensions of the microfoundations category related to individuals and their role in building the digital transforming capability and explaining performance heterogeneity (Felin et al., 2012), which we name digital-savvy skills.

The literature also relates different forms of organisational structure to the microfoundations of capabilities (Felin et al., 2012). Actually, organisational structures influence companies' responses to change (Wilden et al., 2013) and, in the case of digital transformation, the ability to constantly digitally transform. This is because structures specify the conditions that enable and constrain individual and collective action, establishing the context for interactions within an organisation (Felin et al., 2012).

Indeed, structural changes have been highlighted as a critical dimension of every digital transformation endeavour (Hess et al., 2016). Organisational structures focused on traditional 
Zomer T., Neely A. and Martinez V. Digital transforming capability and performance: A microfoundational perspective. International Journal of Operation and Production Management. (Accepted 22/04/20) DOI: 10.1108/IJOPM-06-2019-0444

control systems may hamper the agility needed to operate in a fast-paced digital market (Kane et al., 2017). Command-and-control working environments that are created around clearly defined managerial hierarchies work well in structuring efficiency into the organisation, but they make it much harder for employees to respond rapidly to customers' demands and work more quickly and more collaboratively (Dery et al., 2017). Companies need an agile and nimble structure to execute a digital transformation and sustain the capability to transform in a fast-paced environment (Kane et al., 2016). Also, decentralisation is necessary to sustain dynamic capabilities because it brings managers closer to new technologies, customers and markets (Teece, 2007). Warner and Wager (2019) also posit that incumbents need to redesign internal structures, and this can be achieved through the decentralisation of business units.

Moreover, industry reports have pointed out that digitally mature companies are changing their culture and that taking risks has become a cultural norm. Overcoming aversion to risk has been recognised as a critical characteristic of digital transformation and digitally mature firms (Kane et al., 2017). Therefore, in alignment with the existing literature on the categorisation of micofoundations (Felin et al., 2012), we posit that the context for action and interaction (i.e. the structure and culture) is an essential aspect of promoting and sustaining digital transformation over time and maintaining appropriate value; in other words, it is a microfoundation of the digitally transforming capability.

The literature has also recognised the role of processes in the development and operation of capabilities (Teece, 2007; Felin et al., 2012). When addressing the reconfiguration capability, Teece (2007) points out that the successful calibration of technological and market opportunities, the selection of technologies and product attributes, the design of the business model and the financial commitment of resources to investment opportunities can lead to enterprise growth and profitability. In the reconfiguration of the asset base and business, incumbent firms may focus their search activities on the exploitation of established technological and organisational assets, and they may frame new problems in a manner that is consistent with the enterprise's current knowledge base and business model (Teece, 2007). In the case of digital transformation, Warner and Wager (2019) propose that traditional firms need to build or join digital ecosystems to work with new partners on co-creating opportunities and strategically renew the business; in other words, they need to navigate through innovation ecosystems.

Empirical cases of digital transformation have also shown that companies are creating digital ecosystems and have demonstrated that leadership and technology-based acquisitions 
Zomer T., Neely A. and Martinez V. Digital transforming capability and performance: A microfoundational perspective. International Journal of Operation and Production Management. (Accepted 22/04/20) DOI: 10.1108/IJOPM-06-2019-0444

are relevant aspects (Chen, 2018). Westerman et al. (2012) pointed out that, in order to change their operations, companies need to invest in technology-enabled initiatives; this means that they need to improve their digital intensity. By increasing their IT/business relationships to implement technology-based change, firms improve their transformation management intensity. The literature has also demonstrated that the acquisition of knowledge complementarities makes strategic transformations more likely (Makri et al., 2010). Therefore, in alignment with the previous literature on the categorisation of microfoundations (Felin et $a l ., 2012$ ), we propose that by navigating innovation ecosystems and using other initiatives such as investments and technology-based acquisitions, firms improve their digital intensity. By improving their digital intensity, they increase their digital maturity (Westerman et al., 2012) and can maintain appropriate value and sustain digital transformation initiatives over time.

Thus, following the literature, our proposed model for the microfoundations of digital transforming capability is represented in Figure 1.

Figure 1 around here.

Accordingly, based on existing research, as previously discussed, the digital transforming capability is conceptualised as being composed of three dimensions of microfoundation (Felin et al., 2012): digital-savvy skills (individual dimension), digital intensity (process dimension) and context for action and interaction (structure dimension). Firms need these microfoundations to continuously execute the digital strategy and maintain appropriate value over time. Thus, we hypothesise that there is a positive relationship between digital transforming capability, as built by those components, and a firm's performance, as follows:

H1: A firm's digitally transforming capability, built by individual, processual and structural microfoundations, is positively associated with its business performance.

In other words, organisations with a strong digital transforming capability possess individual, processual and structural microfoundations that support them with continuous strategic renewal to ensure responsiveness and competitiveness in a fast-changing environment. Therefore, we suggest that there is a direct positive relationship between digital transforming capability and the performance of the firm. The identified microfoundations shed 
Zomer T., Neely A. and Martinez V. Digital transforming capability and performance: A microfoundational perspective. International Journal of Operation and Production Management. (Accepted 22/04/20) DOI: 10.1108/IJOPM-06-2019-0444

light on what drives differences in how an important capability for digital transformation is developed and how digital transformation unfolds in firms, as well as its respective performance impact. The details of the sample selection and data analysis to test the proposed model are presented next.

\section{Methods}

\subsection{Research approach and sample selection}

We tested the model presented previously by considering a sample of 427 large companies from different sectors. Large companies were selected to make up the sample because digital transformation in large and incumbent firms remains relatively slow (Sebastian et al., 2017). Although digital technologies present game-changing opportunities and the potential to improve firms' performance (Dalenogare et al., 2018), they may also represent a threat to the value proposition of companies whose success has been built within the pre-digital economy (Sebastian et al., 2017). The digital transformation of large incumbents' business is a highly complex change process and requires a series of strategic decisions (Warner and Wager, 2019). Thus, it is relevant to identify the antecedents that help those firms to build one of the capabilities necessary to compete in a digital environment. Moreover, investigating the microfoundations of the digital transforming capability in a sample of companies that usually struggle to digitally transform, but which have successfully managed the implementation of digital initiatives, supports the search for evidence on the necessary components to build a relevant capability for a successful digital transformation and competitiveness.

In a recent content-analytic review of the state of knowledge about dynamic capabilities, Schilke et al. (2018) recommended the additional use of archival data and empirical proxy variables in dynamic capabilities research. One of the suggested approaches is to measure the inputs to a dynamic capability (Schilke et al., 2018). Therefore, we adopt a positivist approach and assume an objective reality, following this recommendation to investigate the microfoundations of digital transforming capability.

\subsection{Data collection}

We gathered data on public and large firms from multiple databases: Compustat, EDGAR, Mergent Online, Crunchbase, Factiva global news and Glassdoor. These databases have been used in past research (e.g. Bae and Lee, 2020), including studies on technology use/implementation and performance (Aral and Weill, 2007; Raj et al., 2013). The databases 
Zomer T., Neely A. and Martinez V. Digital transforming capability and performance: A microfoundational perspective. International Journal of Operation and Production Management. (Accepted 22/04/20) DOI: 10.1108/IJOPM-06-2019-0444

were also selected based on their strength in terms of content and coverage. For example, Compustat covers approximately $98 \%$ of the world's market capitalisation, with timely data on more than 56,000 companies, and it is commonly used in the academic literature to obtain performance and other relevant data (e.g. Aral and Weill, 2007; Artz et al., 2010). Factiva is one of the best sources of news and business information (Johal, 2009), which was valuable to gathering data on the digital intensity of firms. Mergent Online is considered one of the most complete historical databases available, and it contains a large amount of current data, including daily updates of executives' biographies (Kessler, 2011), which was valuable to gathering data on the microfoundations category related to individuals, for instance. Appendix A provides an overview of each database, including a description of its completeness and the use of data.

The sample firms were selected in a three-stage process. First, we identified large public firms by their size (more than 1,000 employees) because the focus is on the digital transformation of large companies. We collected data for American public firms only because the 10-K filings we used to capture the data on firms' activities are available only for these firms (i.e. an annual report required by the US Securities and Exchange Commission that gives a comprehensive summary of firms' financial performance and activities). We initially selected 1,655 firms. We then removed large and public firms that were born digital (i.e. which emerged in the digital age, founded after 2000). Unlike born-digital organisations, pre-digital organisations need to pursue a huge transformation (Chanias et al., 2019), meaning that they need to develop new capabilities. We also removed some firms classified within the two-digit NAICS code 51 (information sector) and 54 (professional, scientific and technical services sectors) because some, although well established in the market, are mostly digital and/or technology-related businesses. After applying these filters, 985 firms remained in the sample.

Afterwards, we gathered the $10-\mathrm{K}$ filings (9,850 reports) for all the companies over a tenyear period, and we conducted a content analysis of the filings, aiming to identify the firms that were conducting digital transformation initiatives. This was done using a range of keywords related to digital (e.g. digital transformation, digitalisation, digital platforms) and by searching for those keywords in the filings. In a recent McKinsey Global Survey on digital transformation, more than eight out of ten respondent firms said they were undertaking digital transformation efforts in the past five years (Martin, 2018), so we considered ten years to be an appropriate time frame for analysis. We selected 624 firms for which there were at least ten mentions related to some digital initiative in the filings over this ten-year period; this was a 
Zomer T., Neely A. and Martinez V. Digital transforming capability and performance: A microfoundational perspective. International Journal of Operation and Production Management. (Accepted 22/04/20) DOI: 10.1108/IJOPM-06-2019-0444

clear indication that a firm was implementing a digital transformation initiative, even though the strategies may vary. Indeed, one fundamental assumption underlying corporate reporting content analysis studies is that the volume of the disclosure signifies the relative importance of such a disclosure (Unerman, 2000). Thus, we analysed the volume of the disclosures related to digital initiatives and selected the companies that more frequently mentioned digital technologies, digital strategy and digital transformation in their filings. We also conducted a manual check of the fillings to make sure that the selected firms were implementing a digital initiative. A company statement, for example, which provided clear evidence of its digital initiatives, included the following:

'The digital evolution is affecting how we interact with consumers, customers, suppliers, bottlers and other business partners and stakeholders. We believe that our future success will depend in part on our ability to adapt to and thrive in the digital environment. Therefore, one of our top priorities is to digitize our system by, among other things, creating more relevant and more personalised experiences wherever our system interacts with consumers, whether in a digital environment or through digital devices in an otherwise physical environment.'

We did not consider a control group of organisations that are not implementing digital initiatives for comparison because we could not assume that because there is no mention about a digital initiative in the $10-\mathrm{K}$ filing the company is not undertaking any digital transformation effort. Afterwards, we searched for performance information for those firms in the Compustat database, and we found information for 490 firms. As many companies became public firms in the last ten years, they were not included in the analysis. We considered operational and market performance measures because companies with stronger transformation management have been reported as having superior performance in both operational and market aspects (Westerman et al., 2012). Moreover, market value measures have also been used in studies analysing the IT transformation literature (Bharadwaj et al., 2013), and both operational and market measures have been used in studies looking at digital capabilities, as in the case of big data capability (Gupta and George, 2016). Also, we used a three-year time lag to collect performance data, as temporal separation can reduce a potential method bias and longitudinal research possesses superior causal inference ability (Schilke and Goerzen, 2010). Data for the dependent variable was collected for the years 2018 and 2015 and for the independent variables for 2015.

The sample was further reduced when data was not found for the measurement items of the sub-constructs; for instance, as highlighted earlier, having the right digital-savvy leaders in 
Zomer T., Neely A. and Martinez V. Digital transforming capability and performance: A microfoundational perspective. International Journal of Operation and Production Management. (Accepted 22/04/20) DOI: 10.1108/IJOPM-06-2019-0444

place is a root for improving digital maturity and for digital transforming capability. On the Mergent Online database, we searched for data on leaders' backgrounds and skills. Companies for which data for all measurement items was not found were removed from the sample. This process resulted in 427 companies being included in the sample, as shown in Table 1. Next, we present the measures for the latent variables.

Table 1 around here.

\subsection{Variables and operationalisation}

As discussed earlier, we defined digital transforming capability as a firm's ability to execute a digital strategy (Warner and Wager, 2019). Following this, the digital transforming capability construct was conceptualised as a second-order aggregate of three first-order microfoundational constructs - digital-savvy skills, digital intensity and the context for action and interaction, following the categorisation of microfoundations proposed by Felin et al. (2012) (i.e. people, process and structure). Moreover, other studies have suggested that measuring dynamic capabilities as high-order and composite constructs is theoretically and empirically meaningful (Karimi and Walter, 2015). The roots of this are also aligned with the literature on what constitutes organisations with transforming capabilities, such as those where there is an agile and entrepreneurial mindset with a broad approach to external network building (Day and Schoemaker, 2016; Warner and Wager, 2019). The measures of the firstorder constructs were then created using proxies.

As highlighted earlier, empirical studies have recognised that digitally transforming the business requires leaders with the knowledge and experience to drive the transformation continuously, as well as employees with the appropriate digital skills (Kane et al., 2016). Additionally, improving digital maturity and performing digital transformation requires an agile structure and also a digital culture that bolsters risk-taking, agility and collaboration. We also posit that building digital intensity and digital knowledge through partnerships, digital investments and technology-based acquisitions provides the basis for continuously executing digital strategies. The proxies for the measures are summarised below and described in Appendix B in terms of operationalisation, scale and sources.

Digital-savvy leadership (directors and officers). Studies have defined 'digital-savvy' as an understanding that is developed through the experience and education of digital technologies 
Zomer T., Neely A. and Martinez V. Digital transforming capability and performance: A microfoundational perspective. International Journal of Operation and Production Management. (Accepted 22/04/20) DOI: 10.1108/IJOPM-06-2019-0444

and their impact (Weill et al., 2019). Thus, we analysed the proportion of the top management team and board of directors that had an appropriate background for dealing with digital transformation. We conducted a content analysis of 7,252 executives' biographies to identify members with backgrounds in digital, technology and innovation. In our content analysis, we looked for a range of keywords related to digital and innovation in the biographies. Information about the background and skills of the top management team members was gathered from the Mergent Online database. Previous research has already employed a similar approach; Chung and Kang (2019), for instance, analysed the characteristics of chief technology officers and the impact on radical innovation by conducting content analysis on the officers' biographies, as extracted from the companies' annual reports. Completeness of information is ensured, as companies are required to provide up-to-date information in the annual reports.

Digital-savvy workforce. Improving the digital maturity of the workforce is necessary when performing a digital transformation, and firms need digital natives in the workforce (Warner and Wager, 2019). We analysed whether the firms had the digital skills needed to constantly operationalise a digital strategy by gathering data on the proportion of tech- and digital-related positions that became vacant in the analysed period in relation to the total number of job openings in the same period. As previously mentioned, the existing literature has already highlighted that individuals are a fundamental locus of knowledge in organisations, and the mobility of individuals influences organisational capabilities (Felin et al., 2012). This justifies the adoption of the number of individuals entering the organisation as a proxy for analysing improvement in the digital-savvy workforce, necessary to build the digitally transforming capability. We gathered this information from the Glassdoor jobs search. This database has also been used by previous studies to analyse, for instance, IT-related job descriptions (Han and Palvia, 2019).

Risk-taking culture. To determine whether there was a risk-taking culture in a given company, we analysed the number of organisations founded by the ex-employees of the respective firm. We adopted this proxy because it has been stated that an organisation with transforming capabilities is one with an entrepreneurial mindset actively cultivated within the firm (Day and Schoemaker, 2016; Warner and Wager, 2019). Previous research has asserted that organisational culture plays a central role in fostering the entrepreneurial orientation of the firm (Brettel et al., 2015). The culture of an organisation can also strongly affect individuals' 
Zomer T., Neely A. and Martinez V. Digital transforming capability and performance: A microfoundational perspective. International Journal of Operation and Production Management. (Accepted 22/04/20) DOI: 10.1108/IJOPM-06-2019-0444

posturing, including their risk-taking and entrepreneurial posturing (Covin and Slevin, 1991). Employees internalise an organisation's culture, and the place of employment may influence an employee's ability to perceive an entrepreneurial prospect (Agarwal et al., 2004). We thus used the proxy that, if the organisation provides an environment that encourages risk-taking, employees may internalise the culture and might be more likely to perceive opportunities. Also, there is evidence that knowledge-rich firms tend to be 'entrepreneurial hotbeds' and more prone to spawning spin-outs (Agarwal et al., 2004). Knowledge creation is fostered by an organisation climate that stresses risk-taking and experimentation (Smith et al., 2005). Thus, we assume that organisations where there is a strong risk-taking culture are also a knowledgerich environment, creating more conditions for employees to perceive entrepreneurial opportunities. We gathered information on businesses founded by ex-employees of the firms from the Crunchbase database, which has also been used in other studies (e.g. Bae and Lee, 2020).

Nimble and agile structure. We identified how nimble and agile the organisations were by considering the common elements of agile and nimble organisations identified by previous studies (Aghina et al., 2017). Previous research has identified that agile organisations exhibit five trademarks involving strategy, structure, process and technology. These trademarks include a network of teams within a people-centred culture that operates in rapid learning and fast-decision cycles, which are enabled by technology and a common purpose that co-creates value for all stakeholders (Aghina et al., 2017). Additionally, each trademark is associated with several organisational-agility practices. As we are interested in the agility related to the structure within the organisation, we selected the trademarks related to structure (network of empowered teams), process (rapid decision and learning cycles) and people (dynamic people model), and extracted keywords related to each organisational-agility practice in order to measure agility for each firm in our sample. We then conducted a content analysis of news in order to identify agility practices and classify how agile and nimble the selected organisations were. We gathered data from the Factiva global news database about firms' structural change initiatives by searching for a range of keywords defined based on the organisational-agility practices. We performed a content analysis of the selected news to understand these initiatives and we classified organisations by considering the number of agility practices adopted. 
Zomer T., Neely A. and Martinez V. Digital transforming capability and performance: A microfoundational perspective. International Journal of Operation and Production Management. (Accepted 22/04/20) DOI: 10.1108/IJOPM-06-2019-0444

Multi-divisional structure. Previous empirical research has found that functional and departmental silos are one of the main barriers to a company's success in the digital age, and these silos have been correlated with negative performance (Bender and Willmott, 2018). In contrast, it has been claimed that multi-divisional firms can be efficient innovators because these companies decentralise product or service development and decision-making, assigning them to the relevant divisions (Tidd, 2001). We then analysed whether firms have a multidivisional structure, considering that it may help to decentralise decision-making and facilitate digital transformation. We collected data on the proportion of divisional officers, and we gathered this information from the Mergent Online database.

External partnerships and technology-based acquisitions. We collected data on external collaboration as a strategic activity that helps organisations to improve their digital intensity and digital maturity and which helps to build the digital ecosystem (Warner and Wager, 2019). We gathered data from Factiva on the number of partnerships and collaborations for each firm. We then filtered the partnerships and collaborations related to digital innovations using a range of digital- and technology-related keywords. We also gathered data on technology-based acquisitions, as part of the process of building a digital ecosystem and acquiring knowledge. Through technology acquisitions, organisations can expand their knowledge base and enhance their potential for recombination (Ahuja and Katila, 2001). Also, as previously mentioned, the acquisition of knowledge complementarities makes strategic transformations more likely (Makri et al., 2010). We thus analysed the percentage of technology-related acquisitions in digital concerning all acquisitions made by the company in the period, introducing a three-year time lag. We gathered data from the Crunchbase database and classified the acquisitions by considering the categorisation of the companies provided by the database, that is, based on the category of the acquired company and whether these companies' businesses fell within the technological and digital domain.

Digital investments. As discussed earlier, studies have shown that digitally mature companies have high digital intensity. We analysed the percentage of investments in digital concerning all of the investments made by the company, introducing a three-year time lag. We gathered information from the Crunchbase database and classified the investments by considering the categorisation of the companies provided by the database, as explained earlier. 
Zomer T., Neely A. and Martinez V. Digital transforming capability and performance: A microfoundational perspective. International Journal of Operation and Production Management. (Accepted 22/04/20) DOI: 10.1108/IJOPM-06-2019-0444

Business performance. We considered operational and market performance measures because companies succeeding in digital transformation have reported superior performance in both operational and market aspects (Westerman et al., 2012). We considered change in return on assets (ROA), return on sales (ROS) and market capitalisation. Operation- and market-based performance have been considered in other studies for the performance effects of digital capabilities and innovation in general (Gunday et al., 2011; Gupta and George, 2016; Wamba et al., 2017).

In addition, the firm's size, industry and age were used as control variables. Firm age was captured by the number of years since the company's foundation and firm size by the number of employees. Both variables were employed in logarithmical terms because their distribution differed from normality. For the industry sector, a dummy variable was included (Bendig et al., 2018). Other studies on the microfoundations of dynamic capabilities (Bendig et al., 2018) that have analysed the relationship between innovation and performance or digital capabilities and performance have also employed these control variables (Gunday et al., 2011; Akter et al., 2016; Gupta and George, 2016).

\section{Analyses and results}

We applied structural equation modelling (SEM) to examine the proposed model. SEM is useful to determine whether an a priori model is valid, and it is recognised as a valuable tool for testing and advancing theory (Shah and Goldstein, 2006). SEM also provides the flexibility to construct unobservable latent variables, as in the case of digital transforming capability. We followed the approach proposed by Anderson and Gerbing (1988) to estimate the measurement model before the structural model. The preliminary and prerequisite analysis for SEM, that is, exploratory factor analysis (EFA) and confirmatory factor analysis (CFA), were also conducted.

\subsection{Model assessment}

Prior to evaluating the measurement model, an exploratory factor analysis was conducted to confirm the number of factors underlying the model constructs and the pattern of loadings. An EFA was performed using principal component analysis with the VARIMAX orthogonal rotation method, and the prerequisites for EFA were satisfied. The Kaiser-Meyer-Olkin (KMO) measure of sampling adequacy was 0.79 , well above the recommended level of 0.6 and thus 
Zomer T., Neely A. and Martinez V. Digital transforming capability and performance: A microfoundational perspective. International Journal of Operation and Production Management. (Accepted 22/04/20) DOI: 10.1108/IJOPM-06-2019-0444

indicating sampling adequacy (Tabachnick et al., 2007). The Bartlett's test of sphericity was significant $(\mathrm{p}<0.001)$, meeting the suitability requirement $(\mathrm{p}<0.05)$ of the factor analysis (Tabachnick et al., 2007; Williams et al., 2010). The EFA factor solutions were supported by the cumulative percentage of variance extracted, ranging from $45.2 \%$ to $60.3 \%$. Finally, all items loaded highly on the appropriate construct, and there were no significant cross-loadings.

The measurement model was then evaluated prior to the structural model in terms of its construct reliability, unidimensionality, convergent validity and discriminant validity. The first-order constructs are digital-savvy skills, digital intensity, the context for action and interaction and performance. The second-order factor is digitally transforming capability.

We assessed the measurement properties of our scales via a confirmatory factor analysis. The purpose of the CFA was to test the unidimensionality of the multi-item constructs and to eliminate unreliable items. Items that had item-to-construct loadings that were too low were deleted. One item initially defined for the context for action and interaction construct was deleted (the proportion of divisional officers) for having a low loading (0.05). We defined it initially as a proxy based on the claim that multi-divisional firms can be efficient innovators and could be efficient in their approach to renew the resources bases constantly, because these companies decentralise product/service development and decision-making, assigning them to the relevant divisions (Tidd, 2001). This type of structure, however, may also limit the chance to learn new competencies because firms with many divisional boundaries are associated with strategies based on a deepening, instead of broadening, of capabilities (Tidd, 2001).

All of the items loaded significantly on their designated first-order construct. The results of the CFA are presented in Table 2. The factor loadings of the items to the corresponding constructs ranged from 0.50 to 0.90 , and all the loadings are significant $(\mathrm{P}<0.001)$, supporting a convergent validity. We also examined the average variance extracted (AVE) of each construct. The AVE values were all above the suggested criterion of 0.5 , also reflecting unidimensionality (Fornell and Larcker, 1981). These results provide evidence of convergent validity.

Table 2 around here.

We also confirmed the discriminant validity by calculating the square root of the AVEs in the diagonals of the correlation matrix, as shown in Table 3. This test indicates that the measurement model of the constructs is free from redundant items, that is, they are 
Zomer T., Neely A. and Martinez V. Digital transforming capability and performance: A microfoundational perspective. International Journal of Operation and Production Management. (Accepted 22/04/20) DOI: 10.1108/IJOPM-06-2019-0444

conceptually distinct from one another. The square root of the AVE of each construct was higher than its correlations with other constructs, demonstrating that the measurement model had good discriminant validity.

Table 3 around here.

Unidimensionality was also supported by the composite reliability of each construct. The composite reliability prioritises items by their reliability in estimating the measurement model, this being the most robust measure of a construct's internal consistency (Hair et al., 2011; Wamba et al., 2017). The composite reliabilities are also above the acceptable standard of 0.70 (Fornell and Larcker, 1981), as shown in Table 3.

We also evaluated the measurement model using a number of fit indices, including the chisquare; the root mean square error of approximation (RMSEA); goodness of fit index (GFI) for absolute fit (Fullerton et al., 2014); Tucker-Lewis index (TLI) (Tucker and Lewis, 1973); incremental fit index (IFI) (Bollen, 1989); comparative fit index (CFI) for incremental fit (Bentler, 1990); and the ratio of chi-square to degrees of freedom for parsimonious fit. Although there are no minimal established guidelines for what constitutes a good fit (Schermelleh-Engel et al., 2003; Fullerton et al., 2014), there are several suggested parameters for what represents an acceptable fit. An RMSEA value of less than 0.08 is reasonable (Byrne, 2001), and values over 0.90 are acceptable for the GFI, TLI, IFI and CFI (Byrne, 2001). A ratio of the chi-square to degrees of freedom of three or less is a reasonably good indicator (Kline, 1998). The measurement model has a good fit index (Table 2).

In the proposed framework, the digital transforming capability is a higher-order construct composed of digital-savvy skills, the conditions for action and interaction and digital intensity. To establish if the digital transforming capability is a single second-order factor, the null hypothesis that the first-order factors converge to the single higher-order construct was tested (Calantone et al., 2002). Table 4 presents the loadings and fit indices, along with the model fitting the data well. Factor loadings from the measurement items to their respecting first-order constructs range from 0.50 to 0.89 and are significant at $\mathrm{P}<0.001$. Factor loadings from the first-order factors to the second-order factor range from 0.48 to 0.96 and can be considered significant at $\mathrm{P}<0.001$. The measures of fit support the null hypothesis that the first-order factors converge to a single higher-order construct. The ratio of chi-square to the degrees of freedom is 2.47 , RMSEA is 0.06 , GFI is 0.96 , TLI is 0.96 , IFI is 0.98 and CFI is 0.98 . Because 
Zomer T., Neely A. and Martinez V. Digital transforming capability and performance: A microfoundational perspective. International Journal of Operation and Production Management. (Accepted 22/04/20) DOI: 10.1108/IJOPM-06-2019-0444

the model exhibited good measurement properties, the fitness of the structural model can be evaluated.

Table 4 around here.

\subsection{Fitness of the structural equation model and path analysis results}

The ratio of chi-square to the degrees of freedom is 1.69 , indicating an acceptable fit. The RMSEA does not exceed the acceptable fit measure of 0.08 . Each one of the remaining model fit indices shown in Table 5 exceeds the acceptable fit level of 0.90 . Moreover, the proposed path is significant, except for those from the control variables to firm performance. The coefficient on the path from the digital transforming capability to firm performance is $0.20(\mathrm{t}$ $=3.08, \mathrm{P}<0.01)$. Thus, this positive relationship indicates that our hypothesis is confirmed; the firm's ability to digitally transform contributes to sustaining its performance over time.

Table 5 around here.

By confirming the proposed model, our findings offer insights into both theory and practice.

\subsection{Discussion}

Firms need to have the conditions, processes and skills in place that allow them to transform and reconfigure their resource base to maintain appropriate value in a fast-paced digital landscape. Our findings confirm that one of the individual skills necessary to constantly execute a digital initiative is related to digital-savvy skills. It has been reported that senior leadership teams without digitalisation experience are a significant barrier to business transformation (Sawy et al., 2016). Empirical research has also shown that having board members with experience and digital know-how is a financial performance differentiator (Weill et al., 2019). Indeed, an important managerial function to sustain dynamic capabilities is achieving semi-continuous asset orchestration and corporate renewal; therefore, managers with know-how and experience of digital are probably more equipped to perform the constant renewal required in the digital era. The reporting relationship between the leaders involved with digital transformation and the digital mindset of the workforce has also been highlighted 
Zomer T., Neely A. and Martinez V. Digital transforming capability and performance: A microfoundational perspective. International Journal of Operation and Production Management. (Accepted 22/04/20) DOI: 10.1108/IJOPM-06-2019-0444

as relevant (Sia et al., 2016; Singh and Hess, 2017). The changes needed to constantly digitally transform an organisation and for the maintenance of ongoing operations require new skills (Hess et al., 2016). Our results also confirm that firms are investing in digitising their workforce. Other studies investigating new digital and operational capabilities, such as the data analytics capability, have also demonstrated the role of technical skills in promoting the implementation of these new digital initiatives (Gupta and George, 2016). Previous research on critical success factors for technology implementation has already identified that there is a need for team members to be familiar with the new technologies (Co et al., 1998). However, as Kindström et al. (2013) point out, one crucial element when reconfiguring business models is the creation of new mental models, which are crucial to long-term success and continuous innovation. Therefore, firms need a digital mental model disseminated among its leadership and workforce; hence, having people with a digital background was confirmed as being essential, not only because of technical skills that are necessary, but because of the need for a constant change.

Capabilities are built not just on individual skills, but also on the collective learning derived from how employees work together, and on the technology or facilities that the firm has access to (Teece, 2012). Scholars have posited that the accumulation of knowledge resources is a central driver of capability development (Bendig et al., 2018). Indeed, in a digital world, where industry boundaries are permeable, companies need to reconsider their partnership strategy and business ecosystem. As stated earlier, firms need to build or join a digital ecosystem to work with new partners to redefine the speed of collaborative behaviours and transform the business (Warner and Wager, 2019). Our findings confirm that firms that are digitally transforming their business and creating improvements in their performance are investing heavily in increasing their digital intensity through digital partnerships, digital acquisitions and investments. This type of reconfiguration usually involves new and constant investments, mergers and acquisitions (Teece, 2007).

Indeed, when a digital business strategy takes hold in digitally maturing companies, scaling options tend to be based on alliances and partnerships (Bharadwaj et al., 2013). Most of the investments made by the analysed firms were strategic in this sense: they were focused on scaling the business according to an analysis of the descriptions of investments. These digitalrelated acquisitions may be explained by the fact that because these companies have their digital strategies integrated into their business strategies, they may want to absorb the knowledge and take control of it because it will be related to the core business (Hagedoorn and 
Zomer T., Neely A. and Martinez V. Digital transforming capability and performance: A microfoundational perspective. International Journal of Operation and Production Management. (Accepted 22/04/20) DOI: 10.1108/IJOPM-06-2019-0444

Duyesters, 2002). However, a discussion of which strategies are better for increasing digital intensity and digital maturity is not within the scope of this paper.

Additionally, to build and sustain dynamic capabilities, decentralisation must be favoured (Teece, 2007). Our results also confirm that firms are focusing on creating nimble and agile structures, which is necessary to keep reconfiguring the business in a fast-paced digital environment. Agile practices, however, also require an appropriate culture. Our results show the existence of a culture of risk-taking in those organisations. A risk-taking culture indeed supports and sustains innovation (Karimi and Walter, 2015).

Thus, in summary, our primary goal was to investigate the microfoundations of digital transforming capability that help to explain performance heterogeneity. The findings show that the second-order construct has a positive association with the first-order components. Our results also show that digital congruence among the culture, people and structure is necessary to effectively address a continually changing digital landscape, and it is an ingredient to sustained performance, as previously suggested by empirical research (Kane et al., 2016).

\section{Conclusion}

By investigating the microfoundational aspects of an important capability for digital transformation, the paper provides theoretical and practical implications. First, as previously mentioned, there have been calls for more research on how organisations build dynamic capabilities and the microfoundations that help to explain how digital transformation unfolds in practice. This study offers a conceptual framework that links one of the dynamic capabilities for digital transformation to both its microfoundations and performance outcomes. A particular contribution is then the conceptualisation and operationalisation of the construct. Moreover, by testing the framework, this study provides evidence of the relationships between the first-order microfoundations and performance impact of digital transforming capability, which has not been explored in the academic literature. Thus, theoretically, this study extends the microfoundations of dynamic capabilities in a digital transformation context by revealing critical organisational and individual aspects of a digital transformation that, in turn, contribute to performance. The findings indicate that responding to digital disruption depends on holistic combinations of the constituent factors.

In addition, as highlighted previously, digital transformation research has been supported mostly in practice with the emergence of numerous industry reports, but academic literature that tests what has been observed in practice is still in an early stage. Understanding this 
Zomer T., Neely A. and Martinez V. Digital transforming capability and performance: A microfoundational perspective. International Journal of Operation and Production Management. (Accepted 22/04/20) DOI: 10.1108/IJOPM-06-2019-0444

complex phenomenon that has challenged many organisations, however, is of paramount importance for the operations management and strategic management literature, mainly because of the high number of companies that have not been able to cope with the transformational requirements of new digital technologies. Our findings provide a general framework of the relevant antecedents of a digital transforming capability and contribute to the calls in the literature for more research on digital transformation from an organisational perspective. Our results also provide guidance to managers and consultants who are engaged in digital transformation.

Although the main objective was to add to the current literature on digital transformation, this study also contributes to the dynamic capabilities' literature by providing insights on the influence of individual and firm-level factors on the development of dynamic capabilities. Recent literature has started to recognise that the skills of top managers matter in shaping dynamic capabilities, for instance, and our findings have confirmed this.

Obviously, statistical research, especially that which is drawn on archival and secondary data, can capture only particular features of complex phenomena, such as the one studied in the current paper. Other factors may also be relevant as microfoundations of dynamic capabilities in the context of digital transformation (and more specifically for the digital transforming capability), which could not be captured with secondary data. Other microfoundations for seizing, sensing and transforming capabilities and their relationship should be explored in further research by drawing on questionnaire surveys; in addition, their relationships with firms' competitive advantage over time should be analysed. We have been able, however, to improve our understanding of some of the critical dimensions influencing organisational transformation and performance, which were previously suggested only through anecdotal evidence. Another limitation is that we tested our model using only US data. Because digital transformation is a global phenomenon, it is important to analyse the microfoundations of digital transforming capability and other dynamic capabilities in different national cultural contexts to establish generalisability.

More quantitative research will also be valuable in assessing the independent and combined effects of multiple factors. Moreover, a comparison of different digital transformation initiatives, and the capabilities related to them - once the literature has evolved and the conceptual frameworks categorising digital business models have emerged - will shed a more nuanced light on the performance effects of different digital transformation strategies and the 
Zomer T., Neely A. and Martinez V. Digital transforming capability and performance: A microfoundational perspective. International Journal of Operation and Production Management. (Accepted 22/04/20) DOI: 10.1108/IJOPM-06-2019-0444

conditions under which various digital business strategies can be built, leading to improved performance outcomes.

\section{References}

Abebe, M. and Alvarado, D.A. (2013), "Founder-CEO status and firm performance: an exploratory study of alternative perspective", Journal of Strategy and Management, Vol. 6 No. 4, pp. 343-357

Alford, A.W., Jones, J.J. and Zmijewski, M.E. (1994), "Extensions and violations of the statutory SEC Form 10-K filing requirements", Journal of Accounting and Economics, Vol. 17 No. 1-2, pp. 229-254.

Agarwal, R. and Helfat, C.E. (2009), “Strategic Renewal of Organizations”, Organization Science, Vol. 20 No. 2, pp. 281-293.

Aghina, W., Ahlbäck, K., De Smet, A., Fahrbach, C., Handscomb, C., Lackey, G., Lurie, M., Murarka, M., Salo, O., Seem, E. and Woxholth, J. (2017), "The five trademarks of agile organisations", available at: https://www.mckinsey.com/business-functions/organization/ourinsights/the-five-trademarks-of-agile-organizations (accessed 7 April 2020).

Ahuja, G. and Katila, R. (2001), “Technological acquisitions and the innovation performance of acquiring firms: A longitudinal study”, Strategic management journal, Vol. 22 No. 3, pp. 197-220.

Akter, S., Wamba, S.F., Gunasekaran, A., Dubey, R. and Childe, S.J. (2016), "How to improve firm performance using big data analytics capability and business strategy alignment?", International Journal of Production Economics, Vol. 182, pp. 113-131.

Anand, G., Ward, P.T., Tatikonda, M.V. and Schilling, D.A. (2009), "Dynamic capabilities through continuous improvement infrastructure", Journal of Operations Management, Vol. 27, pp. 444-461.

Anderson, J.C. and Gerbing, D.W. (1988), "Structural Equation Modelling in Practice: A Review and Recommended Two-Step Approach”, Psychological Bulletin, Vol. 103 No. 3, pp. 411-423.

Andrevski, G., Brass, D.J. and Ferrier, W.J. (2016), “Alliance portfolio configurations and competitive action frequency”, Journal of Management, Vol. 42 No. 4, pp. 811-837.

Aral, S. and Weill, P. (2007), "IT assets, organizational capabilities, and firm performance: How resource allocations and organizational differences explain performance variation", Organization science, Vol. 18 No. 5, pp. 763-780. 
Zomer T., Neely A. and Martinez V. Digital transforming capability and performance: A microfoundational perspective. International Journal of Operation and Production Management. (Accepted 22/04/20) DOI: 10.1108/IJOPM-06-2019-0444

Artz, K. W., Norman, P. M., Hatfield, D. E. and Cardinal, L. B. (2010), “A longitudinal study of the impact of R\&D, patents, and product innovation on firm performance", Journal of product innovation management, Vol. 27 No. 5, pp. 725-740.

Bae, M.J. and Lee, P.J.M (2020), "How Technological Overlap between Spinouts and Parent Firms Affects Corporate Venture Capital Investments in Spinouts: The Role of Competitive Tension", Academy of Management Journal, in press.

Basole, R.C., Park, H. and Chao, R.O. (2018), "Visual analysis of venture similarity in entrepreneurial ecosystems", IEEE Transactions on Engineering Management, Vol. 66 No. 4, pp. 568-582.

Bender, M. and Willmott, P. (2018), "Digital reinvention: unlocking the how", available at: https://www.mckinsey.com/ /media/McKinsey/Business\%20Functions/McKinsey\%20Digita 1/Our\%20Insights/Digital\%20Reinvention\%20Unlocking\%20the\%20how/Digital-

Reinvention_Unlocking-the-how.ashx (accessed 14 April 2020).

Bendig, D., Strese, S., Flatten, T.C., da Costa, M.E.S. and Brettel, M. (2018), "On microfoundations of dynamic capabilities: A multi-level perspective based on CEO personality and knowledge-based capital”, Long Range Planning, Vol. 51 No. 6, pp. 797-814.

Bentler, P.M. (1990), “Comparative fit indexes in structural models”, Psychological Bulletin, Vol. 107 No. 2, pp. 238-246.

Berman, S.J. (2012), "Digital transformation: opportunities to create new business models", Strategy \& Leadership, Vol. 40 No. 2, pp. 16-24.

Bharadwaj, A., El Sawy, O.A., Pavlou, P.A. and Venkatraman, N. (2013), "Digital business strategy: Toward a next generation of insights", MIS Quarterly: Management Information Systems, Vol. 37 No. 2, pp. 471-482.

Bollen, K.A. (1989), Structural Equations with Latent Variables. Wiley, New York, NY.

Byrne, B.M. (2001), Structural Equation Modelling with Amos: Basic Concepts, Applications, and Programming. Erlbaum, Mahwah, NJ.

Boyer, K.K., Leong, G.K., Ward, P.T. and Krajewski, L.J. (1997), "Unlocking the potential of advanced manufacturing technologies”, Journal of Operations Management, Vol. 15, pp. 331347.

Brettel, M., Chomik, C. and Flatten, T.C. (2015), "How Organizational Culture Influences Innovativeness, Proactiveness, and Risk-Taking: Fostering Entrepreneurial Orientation in SMEs”, Journal of Small Business Management, Vol. 53, pp. 868-885. 
Zomer T., Neely A. and Martinez V. Digital transforming capability and performance: A microfoundational perspective. International Journal of Operation and Production Management. (Accepted 22/04/20) DOI: 10.1108/IJOPM-06-2019-0444

Calantone, R.J., Cavusgil, S.T. and Zhao, Y. (2002), "Learning orientation, firm innovation capability, and firm performance”, Industrial Marketing Management, Vol. 31 No. 6, pp. 515524.

Chanias, S., Myers, M.D. and Hess, T. (2019), "Digital transformation strategy making in predigital organizations: The case of a financial services provider", The Journal of Strategic Information Systems, Vol. 28 No. 1, pp. 17-33.

Chen, O. (2018), “Utour Transformed to Digital Business by Building a Digital Ecosystem”, available at: https://www.gartner.com/document/3843285 (accessed 9 June 2019).

Chen, W. and Srinivasan, S. (2019), "Going Digital: Implications for Firm Value and Performance", available at: https://hbswk.hbs.edu/item/going-digital-implications-for-firmvalue-and-performance (accessed 7th April 2020).

Chung, D. and Kang, M. (2019), "Characteristics of Chief Technology Officers and Radical Innovation", International Journal of Innovation and Technology Management, Vol. 16 No. 3, pp. 1950026-1-1950026-18.

Co, H.C., Patuwo, B.E. and HU, M.Y. (1998), "The human factor in advanced manufacturing technology adoption: An empirical analysis", International Journal of Operations and Production Management, Vol. 18, pp. 87-106.

Covin, J.G. and Slevin, D.P. (1991), “A Conceptual Model of Entrepreneurship as Firm Behavior”, Entrepreneurship Theory and Practice, Vol. 16 No. 1, pp. 7-26.

Dalenogare, L.S., Benitez, G.B., Ayala, N.F. and Frank, A.G. (2018), "The expected contribution of Industry 4.0 technologies for industrial performance", International Journal of Production Economics, Vol. 204, pp. 383-394.

Day, G.S. and Schoemaker, P.J.H. (2016), “Adapting to Fast-Changing Markets and Technologies”, California Management Review, Vol. 58 No. 4, pp. 59-77.

Dery, K., Sebastian, I.M. and van der Meulen, N. (2017), “The Digital Workplace is Key to Digital Innovation”, MIS Quarterly Executive, Vol. 16 No. 2, pp. 135-152.

Eisenhardt, K.M. and Martin, J.A. (2000), “Dynamic capabilities: what are they?”, Strategic Management Journal, Vol. 21, pp. 1105-1121.

Fainshmidt, S. and Frazier, M.L. (2017), "What Facilitates Dynamic Capabilities? The Role of Organizational Climate for Trust”, Long Range Planning, Vol. 50 No. 5, pp. 550-566.

Felin, T., Foss, N.J., Heimeriks, K.H. and Madsen, T.L. (2012), “Microfoundations of Routines and Capabilities: Individuals, Processes, and Structure", Journal of Management Studies, Vol. 49 No. 8, pp. 1351-1374. 
Zomer T., Neely A. and Martinez V. Digital transforming capability and performance: A microfoundational perspective. International Journal of Operation and Production Management. (Accepted 22/04/20) DOI: 10.1108/IJOPM-06-2019-0444

Fornell, C. and Larcker, D.F. (1981), "Evaluating Structural Equation Models with Unobservable Variables and Measurement Error", Journal of Marketing Research, Vol. 18 No. 1, pp. 39-50.

Frank, A.G., Dalenogare, L.S. and Ayala, N.F. (2019), "Industry 4.0 technologies: Implementation patterns in manufacturing companies", International Journal of Production Economics, Vol. 210, pp. 15-26.

Fullerton, R.R., Kennedy, F.A. and Widener, S.K. (2014), "Lean manufacturing and firm performance: The incremental contribution of lean management accounting practices", Journal of Operations Management, Vol. 32 No. 7, pp. 414-428.

Gebauer, H., Saul, C.J., Haldimann, M. and Gustafsson, A. (2017), “Organizational capabilities for pay-per-use services in product-oriented companies", International Journal of Production Economics, Vol. 192, pp. 157-168.

Gunday, G., Ulusoy, G., Kilic, K. and Alpkan, L. (2011), "Effects of innovation types on firm performance", International Journal of Production Economics, Vol. 133 No. 2, pp. 662-676.

Gupta, M. and George, J.F. (2016), "Toward the development of a big data analytics capability", Information \& Management, Vol. 53 No. 8, pp. 1049-1064.

Habib, M. M. and Victor, B. (1991), "Strategy, structure, and performance of US manufacturing and service MNCs: A comparative analysis", Strategic Management Journal, Vol. 12 No. 8, pp. 589-606.

Hagedoorn, J. and Duysters, G. (2002), "External Sources of Innovative Capabilities: The Preferences for Strategic Alliances or Mergers and Acquisitions", Journal of Management Studies, Vol. 39 No. 2, pp. 167-188.

Hair, J.F., Ringle, C.M. and Sarstedt, M. (2011), "PLS-SEM: Indeed a Silver Bullet”, Journal of Marketing Theory and Practice, Vol. 19 No. 2, pp. 139-152.

Han, Y. and Palvia, P. (2019), "Unraveling Implicit Knowledge in Information Technology Jobs", In: AMCIS 2019 Proceedings Association for Information Systems. AIS Electronic Library (AISeL), pp. 1-10.

Hasegan, M.F., Nudurupati, S.S. and Childe, S.J. (2018), "Predicting performance - a dynamic capability view", International Journal of Operations \& Production Management, Vol. 38 No. 11, pp. 2192-2213.

Helfat, C.E. and Peteraf, M.A. (2015), "Managerial cognitive capabilities and the microfoundations of dynamic capabilities", Strategic Management Journal, Vol. 36 No. 6, pp. $831-850$. 
Zomer T., Neely A. and Martinez V. Digital transforming capability and performance: A microfoundational perspective. International Journal of Operation and Production Management. (Accepted 22/04/20) DOI: 10.1108/IJOPM-06-2019-0444

Hess, T., Benlian, A., Matt, C. and Wiesböck, F. (2016), "Options for formulating a digital transformation strategy”, MIS Quarterly Executive, Vol. 15 No. 2, pp. 123-139.

Hodgkinson, G.P. and Healey, M.P. (2011), "Psychological foundations of dynamic capabilities: reflexion and reflection in strategic management", Strategic Management Journal, Vol. 32 No. 13, pp. 1500-1516.

Ji, Y., Rozenbaum, O. and Welch, K.T. (2017), “Corporate culture and financial reporting risk: Looking through the Glassdoor", available at SSRN: https://ssrn.com/abstract=2945745 (accessed 7th April 2020).

Johal, R. (2009), "Factiva: Gateway to Business Information. Journal of Business \& Finance Librarianship”, Journal of Business \& Finance Librarianship, Vol. 15, pp. 60-64.

Jonsson, P. (2000), “An empirical taxonomy of advanced manufacturing technology", International Journal of Operations and Production Management, Vol. 20, pp. 1446-1474.

Kane, G., Palmer, D., Phillips, A. N., Kiron, D. and Buckley, N. (2015), "Strategy, not technology, drives digital transformation", MIT Sloan Management Review, available at: https://sloanreview.mit.edu/ strategy-drives-digital-transformation/ (accessed 10 December 2017).

Kane, G., Palmer D., Phillips, A.N., Kiron, D. and Buckley N. (2016), “Aligning the organisation for its digital future", MIT Sloan Management Review, available at: https://sloanreview.mit.edu/projects/aligning-for-digital-future/ (accessed 9 June 2019).

Kane, G. (2017), Digital Transformation is a misnomer, available at: https://sloanreview.mit.edu/article/digital-transformation-is-a-misnomer/ (accessed 6 April 2019).

Kane, G., Palmer, D., Phillips, A. N., Kiron, D. and Buckley, N. (2017), “Achieving digital maturity”, MIT Sloan Management Review, available at: https://sloanreview.mit.edu/projects/achieving-digital-maturity/ (accessed 10 December 2017).

Karabarbounis, M. and Pinto, S. (2018), "What can we learn from online wage postings? Evidence from Glassdoor”, Economic Quarterly, Vol. 4Q, pp. 173-189.

Karimi, J. and Walter, Z. (2015), “The Role of Dynamic Capabilities in Responding to Digital Disruption: A Factor-Based Study of the Newspaper Industry”, Journal of Management Information Systems, Vol. 32 No. 1, pp. 39-81.

Kenton, W. (2019), "Compustat", available at: https://www.investopedia.com/terms/c/compustat.asp (accessed 30th March 2020). 
Zomer T., Neely A. and Martinez V. Digital transforming capability and performance: A microfoundational perspective. International Journal of Operation and Production Management. (Accepted 22/04/20) DOI: 10.1108/IJOPM-06-2019-0444

Kessler, A. (2011), “Mergent Online”, Journal of Business \& Finance Librarianship, Vol. 16 No. 2, pp. 171-175,

Khin, S. and Ho, T.C.F. (2019), "Digital technology, digital capability and organizational performance: A mediating role of digital innovation", International Journal of Innovation Science, Vol. 11, No. 2, pp. 177-195.

Kindström, D., Kowalkowski, C. and Sandberg, E. (2013), "Enabling service innovation: A dynamic capabilities approach", Journal of Business Research, Vol. 66 No. 8, pp. 1063-1073. Kline, R. B. (1998), Principles and Practice of Structural Equation Modelling, Guilford Press, New York.

Kotha, S. and Swamidass, P. M. (2000), "Strategy, advanced manufacturing technology and performance: empirical evidence from U.S. manufacturing firms", Journal of Operations Management, Vol. 18, pp. 257-277.

Kretschmer, T. and Claussen, J. (2016), “Generational Transitions in Platform Markets-The Role of Backward Compatibility”, Strategy Science, Vol. 1 No. 2, pp. 90-104.

Lanzolla, G., Lorenz, A., Miron-Spektor, E., Schilling, M., Solinas, G. and Christopher, T. (2018), "Digital Transformation: What Is New If Anything?", Academy of Management Discoveries, Vol. 4 No. 3, pp. 378-387.

LeHong, H. and Waller, G.P. (2017), “Digital Business Ambition: Transform or Optimize?”, available at: https:/www.gartner.com/en/documents/3753470/digital-business-ambitiontransform-or-optimize (accessed 9 June 2019).

Liu, D.Y., Chen, S.W. and Chou, T.C. (2011), "Resource fit in digital transformation: Lessons learned from the CBC Bank global e-banking project”, Management Decision, Vol. 49 No. 10, pp. 1728-1742.

Loon, M., Otaye-ebede, L. and Stewart, J. (2020), "Thriving in the New Normal: The HR Microfoundations of capabilities for Business Model Innovation. An Integrated Literature Review", Journal of Management Studies, in press.

Loonam, J., Eaves, S., Kumar, V. and Parry, G. (2018), “Towards digital transformation: Lessons learned from traditional organizations", Strategic Change, Vol. 27 No. 2, pp. 101-109. Luo, N., Zhou, Y. and Shon, J. (2016), "Employee satisfaction and corporate performance: Mining employee reviews on glassdoor.com", In: Proceedings of the 2016 International Conference on Information Systems. 
Zomer T., Neely A. and Martinez V. Digital transforming capability and performance: A microfoundational perspective. International Journal of Operation and Production Management. (Accepted 22/04/20) DOI: 10.1108/IJOPM-06-2019-0444

Makri, M., Hitt, M.A. and Lane, P.J. (2010), “Complementary technologies, knowledge relatedness, and invention outcomes in high technology mergers and acquisitions", Strategic Management Journal, Vol. 31 No. 6, pp. 602-628.

Martelli, J., and Abels, P. (2010), "The education of a leader: Educational credentials and other characteristics of chief executive officers", Journal of Education for Business, Vol. 85 No. 4, pp. 209-217.

Martin, J.F. (2018), "Unlocking success in digital transformations", available at: https://www.mckinsey.com/ /media/McKinsey/Business\%20Functions/Organization/Our\%2 0Insights/Unlocking\%20success\%20in\%20digital\%20transformations/Unlocking-success-indigital-transformations.ashx (accessed 9 June 2019).

Mcdermott, C.M. and Stock, G.N. (1999), "Organizational culture and advanced manufacturing technology implementation”, Journal of Operations Management, Vol. 17, pp. 521-533.

Mikalef, P., Krogstie, J., Pappas, I.O. and Pavlou, P. (2019), "Exploring the relationship between big data analytics capability and competitive performance: The mediating roles of dynamic and operational capabilities”, Information \& Management, in press.

Park, B.J.R., Srivastava, M.K. and Gnyawali, D.R. (2014), "Walking the tight rope of coopetition: Impact of competition and cooperation intensities and balance on firm innovation performance”, Industrial Marketing Management, Vol. 43 No. 2, pp. 210-221.

Parviainen, P., Tihinen, M., Kääriäinen, J. and Teppola, S. (2017), "Tackling the digitalization challenge: How to benefit from digitalization in practice", International Journal of Information Systems and Project Management, Vol. 5 No. 1, pp. 63-77.

Peteraf, M., Di Stefano, G. and Verona, G. (2013), "The elephant in the room of dynamic capabilities: Bringing two diverging conversations together", Strategic Management Journal, Vol. 34, pp. 1389-1410.

Raj, A., Dwivedi, G., Sharma, A., Jabbour, A.B. and Rajak, S. (2019), "Barriers to the adoption of industry 4.0 technologies in the manufacturing sector: An inter-country comparative perspective", International Journal of Production Economics, in press.

Sailer, P., Stutzmann B. and Kobold, L. (2019), "Successful digital transformation - how change management helps you to hold course", available at: https://assets.new.siemens.com/siemens/assets/api/uuid:103ce0a5-2f0b-45d7-837c- 
Zomer T., Neely A. and Martinez V. Digital transforming capability and performance: A microfoundational perspective. International Journal of Operation and Production Management. (Accepted 22/04/20) DOI: 10.1108/IJOPM-06-2019-0444

0bcc7a5083a9/version:1571666625/successfuldigitaltransformationwhitepaperbysiemensiots ervices.pdf (accessed 6 April 2020).

Sawy, O.A.E., Amsinck, H., Kræmmergaard, P. and Vinther, A.L. (2016), "How LEGO built the foundations and enterprise capabilities for digital leadership”, MIS Quarterly Executive, Vol. 15 No. 2, pp. 141-166.

Schermelleh-Engel, K., Moosbrugger, H. and Müller, H. (2003), "Evaluating the fit of structural equation models: Tests of significance and descriptive goodness-of-fit measures", MPR-online, Vol. 8, pp. 23-74.

Schilke, O. and Goerzen, A. (2010), “Alliance Management Capability: An Investigation of the Construct and Its Measurement”, Journal of Management, Vol. 36, pp. 1192-1219.

Schilke, O., Hu, S. and Helfat, C.E. (2018), "Quo Vadis, Dynamic Capabilities? A ContentAnalytic Review of the Current State of Knowledge and Recommendations for Future Research", Academy of Management Annals, Vol. 12 No. 1, pp. 390-439.

Sebastian, I.M., Moloney, K.G., Ross, J.W., Fonstad, N.O., Beath, C. and Mocker, M. (2017), "How big old companies navigate digital transformation", MIS Quarterly Executive, Vol. 16 No. 3, pp. 197-213.

Shah, R. and Goldstein, S.M. (2006), "Use of structural equation modeling in operations management research: Looking back and forward", Journal of Operations Management, Vol. 24 No. 2, pp. 148-169.

Sia, S.K., Soh, C. and Weill, P. (2016), "How DBS bank pursued a digital business strategy", MIS Quarterly Executive, Vol. 15 No. 2, pp. 105-121.

Singh, A. and Hess, T. (2017), "How chief digital officers promote the digital transformation of their companies”, MIS Quarterly Executive, Vol. 16 No. 1, pp. 1-17.

Smith, K.G., Collins, C.J. and CLARK, K.D. (2005), “Existing knowledge, knowledge creation capability, and the rate of new product introduction in high-technology firms", Academy of Management Journal, Vol. 48, pp. 346-357.

Svahn, F., Mathiassen, L. and Lindgren, R. (2017), "Embracing digital innovation in incumbent firms: How Volvo Cars managed competing concerns", MIS Quarterly: Management Information Systems, Vol. 41 No. 1, pp. 239-253.

Tabachnick, B. G., Fidell, L. S. and Ullman, J. B. (2007), Using multivariate statistics, Pearson, Boston. 
Zomer T., Neely A. and Martinez V. Digital transforming capability and performance: A microfoundational perspective. International Journal of Operation and Production Management. (Accepted 22/04/20) DOI: 10.1108/IJOPM-06-2019-0444

Teece, D.J. (2007), "Explicating dynamic capabilities: the nature and microfoundations of (sustainable) enterprise performance", Strategic Management Journal, Vol. 28 No. 13, pp. 1319-1350.

Teece, D.J. (2012), “Dynamic Capabilities: Routines versus Entrepreneurial Action”, Journal of Management Studies, Vol. 49 No. 8, pp. 1395-1401.

Teece, D.J. (2014), “The Foundations of Enterprise Performance: Dynamic and Ordinary Capabilities in an (Economic) Theory of Firms", Academy of Management Perspectives, Vol. 28 No. 4, pp. 328-352.

Teece, D.J., Pisano, G. and Shuen, A. (1997), "Dynamic capabilities and strategic management", Strategic Management Journal, Vol. 18 No. 7, pp. 509-533.

Tidd, J. (2001), "Innovation management in context: environment, organization and performance", International Journal of Management Reviews, Vol. 3 No. 3, pp. 169-183.

Tortorella, G.L. and Fettermann, D. (2018), "Implementation of Industry 4.0 and lean production in Brazilian manufacturing companies", International Journal of Production Research, Vol. 56, pp. 2975-2987.

Tortorella, G.L., Vergara, A.M.C., Garza-Reyes, J.A. and Sawhney, R. (2020), “Organizational learning paths based upon industry 4.0 adoption: An empirical study with Brazilian manufacturers”, International Journal of Production Economics, Vol. 219, pp. 284-294.

Tucker, L.R. and Lewis, C. (1973), "A reliability coefficient for maximum likelihood factor analysis", Psychometrika, Vol. 38, pp. 1-10.

Tumbas, S., Berente, N. and vom Brocke, J. (2017), “Three types of chief digital officers and the reasons organizations adopt the role", MIS Quarterly Executive, Vol. 16 No. 2, pp. 121134.

Unerman, J. (2000), "Methodological issues - Reflections on quantification in corporate social reporting content analysis", Accounting, Auditing \& Accountability Journal, Vol. 13 No. 5, pp. 667-681.

Vial, G. (2019), "Understanding digital transformation: A review and a research agenda", Journal of Strategic Information Systems, Vol. 28 No. 2, pp. 118-144.

Wamba, S.F., Gunasekaran, A., Akter, S., Ren, S.J.-f., Dubey, R. and Childe, S.J. (2017), “Big data analytics and firm performance: Effects of dynamic capabilities", Journal of Business Research, Vol. 70, pp. 356-365. 
Zomer T., Neely A. and Martinez V. Digital transforming capability and performance: A microfoundational perspective. International Journal of Operation and Production Management. (Accepted 22/04/20) DOI: 10.1108/IJOPM-06-2019-0444

Warner, K.S.R. and Wager, M. (2019), "Building dynamic capabilities for digital transformation: An ongoing process of strategic renewal”, Long Range Planning, Vol. 52 No. 3, pp. 326-349.

Weill, P., Apel, T., Woerner, S.L and Banner J.S. (2019), “It Pays to Have a Digitally Savvy Board", available at: https://sloanreview.mit.edu/article/it-pays-to-have-a-digitally-savvyboard/ (accessed 9 June 2019).

Weking, J., Stöcker, M., Kowalkiewicz, M., Böhm, M. and Krcmar, H. (2019), "Leveraging industry 4.0 - A business model pattern framework", International Journal of Production Economics, in press.

Westerman, G., Tannou, M., Bonnet, D., Ferraris, P. and McAfee A. (2012), "The digital Advantage: How digital leaders outperform their peers in every industry", available at: https://www.capgemini.com/resources/the-digital-advantage-how-digital-leaders-outperformtheir-peers-in-every-industry/ (accessed 10 December 2017).

Wilden, R., Gudergan, S.P., Nielsen, B.B. and Lings, I. (2013), "Dynamic Capabilities and Performance: Strategy, Structure and Environment”, Long Range Planning, Vol. 46 No. 1, pp. $72-96$.

Williams, B., Onsman, A. and Brown, T. (2010), "Exploratory factor analysis: A five-step guide for novices", Australasian Journal of Paramedicine, Vol. 8 No. 3, pp. 1-13. 
Zomer T., Neely A. and Martinez V. Digital transforming capability and performance: A microfoundational perspective. International Journal of Operation and Production Management. (Accepted 22/04/20) DOI: 10.1108/IJOPM-06-2019-0444

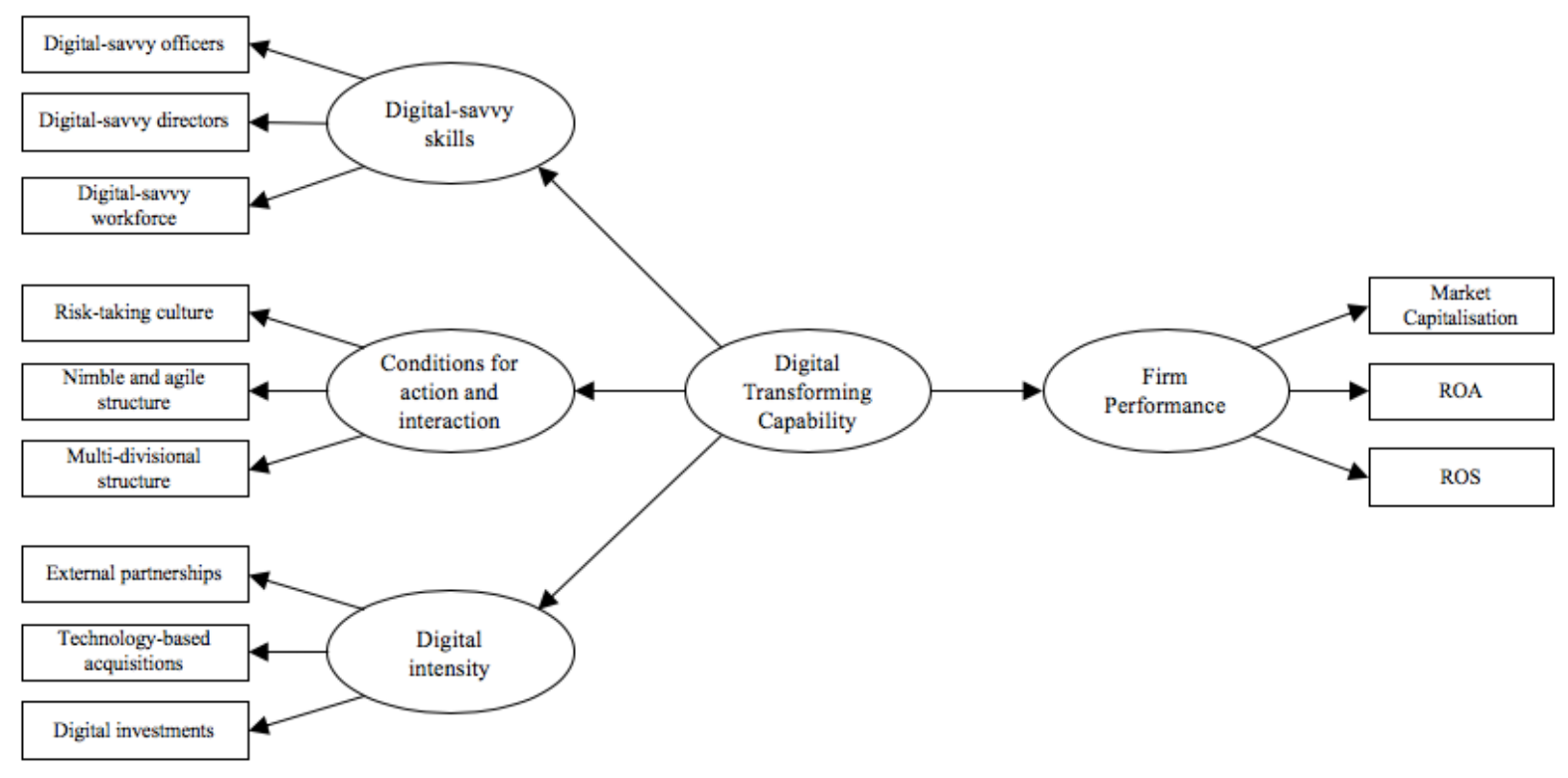

Figure 1. Theoretical model 
Table 1. Sectoral composition of the sample

\begin{tabular}{clc}
\hline NAICS codes & Sector & Count \\
\hline $31-33$ & Manufacturing & 213 \\
$44-45$ & Retail trade & 42 \\
42 & Wholesale trade & 28 \\
$48-49$ & Transportation and warehousing & 27 \\
52 & Finance and insurance & 22 \\
72 & Accommodation and food services & 17 \\
53 & Real estate and rental and leasing & 15 \\
22 & Utilities & 14 \\
56 & Administrative and support and waste & 14 \\
23 & management and remediation services & 11 \\
21 & Construction & 10 \\
62 & Mining, quarrying and oil and gas extraction & 7 \\
81 & Health care and social assistance & 3 \\
61 & Other services (except public administration) & 2 \\
71 & Educational services & 2 \\
\hline
\end{tabular}


Table 2. Parameter estimates for measurement relations

\begin{tabular}{|c|c|c|c|c|}
\hline Construct & Indicator & Loading & p-value & t-value \\
\hline \multirow[t]{3}{*}{ Digital-savvy skills } & $\begin{array}{l}\text { Digital-savvy } \\
\text { officers }\end{array}$ & 0.76 & $<0.001$ & \\
\hline & $\begin{array}{l}\text { Digital-savvy } \\
\text { directors }\end{array}$ & 0.87 & $<0.001$ & 12.93 \\
\hline & $\begin{array}{l}\text { Digital-savvy } \\
\text { workforce }\end{array}$ & 0.50 & $<0.001$ & 9.56 \\
\hline \multirow[t]{3}{*}{ Digital intensity } & $\begin{array}{l}\text { External } \\
\text { partnerships }\end{array}$ & 0.80 & $<0.001$ & \\
\hline & $\begin{array}{l}\text { Technology- } \\
\text { based } \\
\text { acquisitions }\end{array}$ & 0.61 & $<0.001$ & 10.99 \\
\hline & $\begin{array}{l}\text { Digital } \\
\text { investments }\end{array}$ & 0.60 & $<0.001$ & 11.00 \\
\hline \multirow[t]{2}{*}{$\begin{array}{l}\text { Conditions for action } \\
\text { and interaction }\end{array}$} & $\begin{array}{l}\text { Risk-taking } \\
\text { culture }\end{array}$ & 0.72 & $<0.001$ & \\
\hline & $\begin{array}{l}\text { Nimble and agile } \\
\text { structure }\end{array}$ & 0.90 & $<0.001$ & 13.08 \\
\hline \multirow[t]{3}{*}{ Performance } & $\begin{array}{l}\text { Market } \\
\text { capitalisation }\end{array}$ & 0.68 & $<0.001$ & \\
\hline & ROA & 0.71 & $<0.001$ & 11.14 \\
\hline & ROS & 0.78 & $<0.001$ & 11.01 \\
\hline
\end{tabular}

Table 3. AVE, composite reliabilities and construct intercorrelations

\begin{tabular}{lcccccc}
\hline & CR & AVE & $\begin{array}{c}\text { Digital- } \\
\text { savvy skills }\end{array}$ & $\begin{array}{c}\text { Digital } \\
\text { intensity }\end{array}$ & $\begin{array}{c}\text { Conditions } \\
\text { for action/ } \\
\text { interaction }\end{array}$ & Performance \\
\hline $\begin{array}{l}\text { Digital-savvy } \\
\text { skills }\end{array}$ & 0.78 & $56 \%$ & $\mathbf{0 . 7 5}$ & & & \\
$\begin{array}{l}\text { Digital intensity } \\
\begin{array}{l}\text { Conditions for } \\
\text { action and }\end{array}\end{array}$ & 0.75 & $54 \%$ & 0.29 & $\mathbf{0 . 7 4}$ & & \\
interaction & 0.80 & $67 \%$ & 0.08 & 0.19 & $\mathbf{0 . 8 2}$ & \\
Performance & 0.77 & $53 \%$ & 0.02 & 0.14 & 0.02 & $\mathbf{0 . 7 3}$ \\
\hline
\end{tabular}

The square roots of the AVE are shown in the diagonal. 
Zomer T., Neely A. and Martinez V. Digital transforming capability and performance: A microfoundational perspective. International Journal of Operation and Production Management. (Accepted 22/04/20) DOI: 10.1108/IJOPM-06-2019-0444

Table 4. Digital transforming capability second-order measurement model

\begin{tabular}{|c|c|c|c|c|}
\hline Construct & Indicator & Loading & p-value & t-value \\
\hline \multicolumn{5}{|l|}{ First-order } \\
\hline \multirow[t]{3}{*}{ Digital-savvy skills } & Digital-savvy officers & 0.76 & $<0.001$ & \\
\hline & Digital-savvy directors & 0.87 & $<0.001$ & 12.94 \\
\hline & Digital-savvy workforce & 0.50 & $<0.001$ & 9.56 \\
\hline \multirow[t]{3}{*}{ Digital intensity } & External partnerships & 0.80 & $<0.001$ & \\
\hline & Technology-based acquisitions & 0.62 & $<0.001$ & 10.94 \\
\hline & Digital investments & 0.60 & $<0.001$ & 10.88 \\
\hline \multirow[t]{2}{*}{$\begin{array}{l}\text { Conditions for action and } \\
\text { interaction }\end{array}$} & Risk-taking culture & 0.72 & $<0.001$ & \\
\hline & Nimble and agile structure & 0.89 & $<0.001$ & 13.17 \\
\hline \multicolumn{5}{|l|}{ Second-order } \\
\hline \multirow[t]{3}{*}{$\begin{array}{l}\text { Digital transforming } \\
\text { capability }\end{array}$} & Digital-savvy skills & 0.96 & & \\
\hline & Digital intensity & 0.48 & $<0.001$ & 6.68 \\
\hline & Conditions for action and interaction & 0.84 & $<0.001$ & 7.01 \\
\hline
\end{tabular}


Zomer T., Neely A. and Martinez V. Digital transforming capability and performance: A microfoundational perspective. International Journal of Operation and Production Management. (Accepted 22/04/20) DOI: 10.1108/IJOPM-06-2019-0444

Table 5. Results of the path analysis

\begin{tabular}{|c|c|c|c|c|c|}
\hline Paths modelled & & & Loading & p-value & t-value \\
\hline \multicolumn{6}{|l|}{ Hypothesis } \\
\hline $\begin{array}{l}\text { Digital transforming } \\
\text { capability }\end{array}$ & $\rightarrow$ & Performance & 0.20 & 0.002 & 3.08 \\
\hline \multicolumn{6}{|l|}{ Control variables } \\
\hline Firm age & $\rightarrow$ & Performance & 0.07 & 0.231 & 1.20 \\
\hline Firm size & $\rightarrow$ & Performance & 0.07 & 0.241 & 1.17 \\
\hline Industry dummy 1 & $\rightarrow$ & Performance & -0.07 & 0.208 & -1.26 \\
\hline Industry dummy 2 & $\rightarrow$ & Performance & -0.07 & 0.222 & -1.22 \\
\hline Industry dummy 3 & $\rightarrow$ & Performance & 0.05 & 0.417 & 0.81 \\
\hline Industry dummy 4 & $\rightarrow$ & Performance & -0.05 & 0.337 & -0.96 \\
\hline Industry dummy 5 & $\rightarrow$ & Performance & 0.03 & 0.562 & 0.58 \\
\hline Industry dummy 6 & $\rightarrow$ & Performance & 0.00 & 0.959 & 0.05 \\
\hline
\end{tabular}

Goodness of fit $\chi^{2}=202.79 ; d f=120 ; \mathrm{GFI}=0.91 ; \mathrm{TLI}=0.93, \mathrm{CFI}=0.95 ; \mathrm{IFI}=0.95$, RMSEA $=0.04$ 